\title{
Study on the Problems of Transferring the Proceeds of Crime under the Mainland-Taiwan Reciprocal Judicial Assistance
}

\author{
Anmin Lin \\ Minjiang University, \\ Minjiang, Fujian
}

\begin{abstract}
In this paper, we conduct research on the problems of transferring the proceeds of crime under the Mainland-Taiwan reciprocal judicial assistance. At present, the cross-border economic crimes are frequent, so that the cross-border money laundering rate is induced greatly. The disputes about the cross-border crime criminal jurisdiction and the mutual recognition on criminal judgment are still not solved, but the general procedural issues in transferring the proceeds of crime under the mainland-Taiwan reciprocal judicial assistance are basically solved in the Points made by Taiwan and are worthy of praise. We review the latest research on the relate topics to form the better study.
\end{abstract}

Keywords- Crime, Mainland-Taiwan, Reciprocal Judicial Assistance, Review.

\section{Introduction}

In June 2013, the money stolen from Taiwan residents

In June 2013, the money stolen from Taiwan residents in a telecommunication fraud case was returned in accordance with the trial of Hangzhou Intermediate People's Court, and this was the first case completed under the Mainland-Taiwan reciprocal judicial assistance. In April 2014, the money stolen from Taiwan residents in another telecommunication fraud case was returned in accordance with the trial of Zhangzhou Intermediate People's Court, and this was the second case completed under the Mainland-Taiwan reciprocal judicial assistance [1]. Along with the increasingly frequent
Mainland-Taiwan exchanges, this kind of cases will be more, but there are still many problems of transferring the proceeds of crime under the mainland-Taiwan reciprocal judicial assistance currently. Therefore, this aspect is worthy of attention and research [2].

\section{Uncertainties of the booties to be transferred}

In article 9 of the Agreement on Cross-strait Cooperation in Combating Crimes under Mutual Judicial Assistance (hereinafter referred to as Nanjing Agreement), "transferring booties" is applied, but the concept of "proceeds of crime" is not consistently understood by cross-strait scholars. The different viewpoint of the scholars is about whether res incorporales property interest, the income obtained by selling off or transferring the properties from crimes and how to determine the transferrable amount are included.

In accordance with article 9 of Nanjing Agreement, cross-strait judicial organs shall cooperate with each other with regard to "transferring the proceeds of crime". Literally, the proceeds of crime just include gains obtained in crimes and the income obtained by selling off or transferring the properties from crimes". The income obtained by selling off or transferring the properties from crimes" should be understood as the cash discount obtained by selling off the properties from crimes. It can be seen that the proceeds of crime are generally referred to as the gains obtained in crimes in Nanjing Agreement. But "the proceeds of crime", "gains and incomes from crimes", and "criminal assets" are differently defined and need to be discussed. 
The proceeds of crime refer to the money and booties obtained from crimes. The "stolen goods" in the crime of stolen goods stipulated in article 312 of the criminal law amendment 2006 was replaced with "gains and incomes obtained from crimes". In other words, stolen goods not only include gains from crimes, but also incomes from crimes. Since then, China mainland accessed to some international conventions including United Nations Convention against Corruption (UNCAC), and thus, China mainland began to understand the criminal assets sharing system [3]. Legal professionals in mainland defined this concept from the perspective of criminal asset recovery and believed "the proceeds of crime mainly refer to gains, incomes, and tools from crimes and also any items, assets or capital related to criminal behaviors". Currently, the point of view to expand the proceeds of crime is recognized by many professionals in law theoretical and practice cycles [4].

Generally, in the mainland criminal law, the proceeds of crime is mainly embodied in article 64: all properties obtained illegally obtained by criminals shall be recovered or restituted under orders; the lawful property of the victims shall be returned timely; contraband and the possessions of criminals in crime shall be confiscated. All the confiscated properties and fines shall be turned over to the national treasury, but shall not be personally misappropriated or processed. In addition, a similar provision is available in article 234 of the mainland criminal procedure law: the public security organs, people's procuratorate, and people's court shall properly keep and manage the suspects and defendants' properties and fruits that are closed down, detained, and frozen for the sake of examination, and also make a list and transfer them in accordance with the specific cases. Any units or individuals shall not misappropriate them or dispose of them. The lawful property of the victims shall be returned to them without delay. The closed down, detained, and frozen properties and fruits are timely processed in accordance with the trail of the people's court, and the rest of these properties will be turned over to the national treasury. Seen from the details in the above two provisions, the proceeds of crime, incorporated in the processing, apparently include the gains from crimes, the incomes from crimes, and also the tools of crimes and other properties.

Taiwan's definition on the proceeds of crime is not identical with the mainland's definition. In Taiwan, the proceeds of crime, stipulated in the criminal law, are restricted to res corporals and do not include intangible property interests. Specifically, the proceeds of crime are restricted to the original gains or generated items from crimes and do not include the money or items obtained by selling off gains from crimes or [5].

\section{The principles of transferring the proceeds of crime under the Mainland-Taiwan reciprocal judicial assistance and returning the proceeds of international crime}

In mainland criminal law, different approaches are applied to treat the victim's property, contraband, and the possessions of criminal offenders. Criminal offenders shall return the victim's property; the contraband beyond the scope of the victim's property, the possessions of criminal offenders, and other proceeds of crime are forfeited to the national treasury.

Now that the contraband beyond the scope of the victim's property is forfeited to the national treasury, transferring the proceeds of crime does not exist. To this type of forfeited proceeds of cross-border crime, there are no specific provisions in the law in China, so the international convention and the international or interregional judicial agreement are applied. In recent years, China mainland closely contacts with other countries and region, and also pays more attention to the international cooperation in transferring the proceeds of crime. These principles can be references in transferring the proceeds of crime under the Mainland-Taiwan reciprocal judicial assistance.

In fact, the principle of sharing the proceeds of international crime is used by China mainland and Hong Kong for reference to handle this type of 
contraband beyond the scope of the victim's property [6].

\section{Confusion about the Mainland-Taiwan judicial procedures to transfer the proceeds of crime}

Some scholars think that transferring the proceeds of crime is less important and controversial but more complicated in comparison with transferring the criminal suspects, and the related issues mainly include the model of transferring the proceeds of crime, the confirmation of the valid trial on the supplicant, the scope of the proceeds of crime, the responsibility for bearing the cost of transferring the proceeds of crime [7]. Just because of various issues involved in the judicial procedures to transfer the proceeds of crime, the judicial procedures issues are only generally described in Nanjing Agreement.

Mainland public security, procuratorate, and court shall have the right to press for payment afterwards and confiscate the proceeds of crime. In China mainland, specialized legislation about international or interregional judicial assistance in criminal cases is still absent; the cases about transferring the proceeds of crime often appear between mainland China and Hong Kong/Macao/Taiwan, but no other relevant provisions except ambiguous stipulation are available in in Nanjing Agreement. After Nanjing Agreement was signed, the supreme people's court in China mainland issued Agreement about the Mainland-Taiwan Service of Documents and the Investigation and Collection of Evidences in Related Cases in June 2011. In 2013, Answers to the Practical Operation Questions in the Process of the People's Court to Handle the Cases under the Mainland-Taiwan Reciprocal Judicial Assistance was issued, in which the related questions about the Mainland-Taiwan Reciprocal Judicial Assistance are specified. But the clear and explicit rules about the operation of the Mainland-Taiwan Reciprocal Judicial Assistance are unavailable from public security department; the provisions from the supreme people's court about transferring the proceeds of crime are vague, and the details in transferring the proceeds of crime are not provided [8].

On January 3, 2011, Points in the Mainland-Taiwan Investigation and Collection of Evidences and Transferring the Proceeds of Crime was released, in which the relevant procedure questions about transferring the proceeds of crime are specifically provided. According to the provisions of the law and the points in Taiwan, the request body is the "legal department" if Taiwan department requests a transfer of the proceeds of crime, and therefore, Taiwan's prosecutors shall approve a written request and attach the relevant data and write a letter for asking the legal department to raise a request of mutual assistance via the competent department of China mainland. Also, the body in Taiwan to accept the request is also legal department. Then, the legal department notices procuratorial organs to perform the request of the mainland, and thus, the assigned prosecutors are permitted to voluntarily command procuratorial officers, judicial personnel or judicial polices to perform the request.

In Taiwan, the legal department is the main subject to contact the mainland - it will provide assistance to the mainland as long as the request for transferring the proceeds of crime is launched, and two-stage procedures are only spent. When prosecutor are deciding whether to help transfer the proceeds of crime, they first need to examine and verify the request for transferring the proceeds of crime and also confirm the crime income that is not confiscated by Taiwan's court, under the condition that in Taiwan, there are no owners to claim for the proceeds or gains of crime, or there are no agreements available from the owners. For example, Taiwan's court has declared to confiscate the requested proceeds of crime, and then the disputes on the jurisdiction of both sides over the cases or the coordination processing of associated cases may be involved. 


\section{Improving the mainland-Taiwan reciprocal judicial assistance to transfer the proceeds of crime}

\subsection{Determining the scope of the proceeds of crime}

Because there are no clear and explicit provisions available from both sides with regard to transferring the proceeds of crime, further provisions are necessarily made by both sides in terms of judicial practice or agreement related to transferring the proceeds of crime, aiming to clearly and explicitly define the scope of the transferred proceeds of crime as well as the mainland-Taiwan reciprocal judicial assistance.

The purpose of Nanjing Agreement is for jointly blowing crimes, and the economic crimes and corruption crimes such as embezzlement, breach of trust, fraud, money laundering, and counterfeiting or altering currency and securities are crimes emphatically attached by both sides, so effectively transferring the proceeds of crime is an important procedure guarantee for both sides to crack down on crimes commonly [9]. Based on the concerns about the narrow-mindedness of the scope of proceeds of crime provided by Taiwan, Taiwan scholars have proposed that the proceeds of crime necessarily include both tangible and intangible property interests as well as the belongings of the willful third party but are not limited to the belongings of offenders - the proceeds of crime necessarily include the income obtained by selling off properties from crimes, but are not limited to the original gains of offenders [10].

\subsection{Determining the principle of sharing criminal assets}

Currently, in Nanjing Agreement, the principle of sharing criminal assets is not recognized by both sides, but the cost of the mutual assistance is exempted. Although the free cost of the mutual assistance conforms to the principle of fairness and morality, the judicial organs on both sides do not have more enthusiasm for providing assistance to the cases unrelated with them if the criminal assets sharing system is not recognized, especially under the condition that the current cross-strait judicial authorities are struggling to cope with the jurisdiction cases [11].

The principle of sharing criminal assets has not been recognized by both sides yet, and the provision (the government shall confiscate the properties out of the scope of the victim's property) makes the proceeds of crimes in cases without a victim not to be transferred in practice.

In addition, there is no research to compare the inflow volumes of the proceeds of crimes in both sides using empirical methods now, but the proceeds of crimes tend to unidirectionally flow to Taiwan in terms of the multiple cross-border telecom fraud crimes in recent years.

\subsection{Determining the procedure for transferring the proceeds of crimes}

Now, the principles about cooperatively recovering the criminal assets are indistinct in terms of the international treaties concluded or joined by Mainland China [12]. If further provisions are still not made or the detailed rules are not tacitly understood by both sides in terms of the procedures for transferring the proceeds of crimes, coordination will be only applicable in cases and this will not achieve the expected efficiency.

At present, the cross-border economic crimes are frequent, so that the cross-border money laundering rate is induced greatly [13]. Thus, the demand for transferring the proceeds of crimes in cases is increasing, but only the proceeds of fraud crime are transferred.

\section{Conclusion}

The disputes about the cross-border crime criminal jurisdiction and the mutual recognition on criminal judgment are still not solved, but the general procedural issues in transferring the proceeds of crime under the mainland-Taiwan reciprocal judicial assistance are basically solved in the Points made by Taiwan and are worthy of 
praise. Instead, the mainland, where the proceeds of crime are output, does not provide any detailed regulations on the procedures for transferring the proceeds of crime. This may be an important reason why the cross-border crimes are not greatly attached by the mainland government.

\section{References}

[1] Weihan Yang, Lihua Qiu. The First Success to Transfer the Proceeds of Crime under the Mainland-Taiwan Reciprocal Judicial Assistance to the Victim of Taiwan [R]. http://news.xinhuanet.com/legal/2013-06/13/ c_116137223.htm, April 20, 2014.

[2] Yadong Wu. The First Success to Transfer the Proceeds of Crime from Fujian under the Mainland-Taiwan Reciprocal Judicial Assistance to the Victim of Taiwan [R]. http://www.legaldaily.com.cn/index/content/2 014-04/04/content_5429228.htm?node=209 08, April 20, 2014.

[3] Jinbiao Yang. The Meaning of the "Gains of Crime" in Crime of Steeling Goods [J]. Social Science, 2008 (02), p.122.

[4] Lei Chen. Discussion on the Legal Bases and Main Methods of China in the International Cooperation to Recover Stolen Money or Goods [J]. Research on Rule of Law, 2013 (12), p.32.

[5] Zhengyi Zeng. Study on "Transferring the Proceeds of Crime" in the Mainland-Taiwan Agreement about Providing Reciprocal Judicial Assistance [J]. The Collection of the Papers on the Eighth Police Theory Seminar of Cross-Strait Areas (including Hong Kong and Macau), p.399.

[6] Zhengyi Zeng. Study on "Transferring the Proceeds of Crime" in the Mainland-Taiwan Agreement about Providing Reciprocal Judicial Assistance $[\mathrm{J}]$. The Collection of the
Papers on the Eighth Police Theory Seminar of Cross-Strait Areas (including Hong Kong and Macau) in 2013, p.406.

[7] Yan'an Shi. Discussion on the Recovery and Transfer of China's Interregional Cross-border Stolen Money or Goods [J]. Study on Two Systems in One Country, 2011 (4), p.85.

[8] Zhengyi Zeng. Study on "Transferring the Proceeds of Crime" in the Mainland-Taiwan Agreement about Providing Reciprocal Judicial Assistance [J]. The Collection of the Papers on the Eighth Police Theory Seminar of Cross-Strait Areas (including Hong Kong and Macau) in 2013, p.409.

[9] Yinghui Song, Ting He. Independent Property Confiscation in Interregional Cooperation $[\mathrm{J}]$. People's Procuratorial Semimonthly, 2011 (05), p.10.

[10] Zhengyi Zeng. Study on "Transferring the Proceeds of Crime" in the Mainland-Taiwan Agreement about Providing Reciprocal Judicial Assistance [J]. The Collection of the Papers on the Eighth Police Theory Seminar of Cross-Strait Areas (including Hong Kong and Macau) in 2013, p.408.

[11] Shuyu Zeng. A Review of the Criminal Judicial Cooperation Model in Agreement on Cross-strait Cooperation in Combating Crimes under Mutual Judicial Assistance [J]. Furen Law, 2011 (06), p.114.

[12] Feng Huang. The Questions of Procedure to Request Foreign Criminal Judicial Assistance [J]. People's Procuratorial Semimonthly, 2011 (13), p.8.

[13]Anmin Lin. Dilemma in the Cross-strait Cooperation to Crack Down on Cross-border Money Laundering Crime [J]. Shanghai Finance, 2014 (06), p.40. 